\section{Publications should include an animal-welfare section}

SIR - A large majority of the public supports the principle of animal experimentation to improve biological knowledge, human and veterinary health, nature conservation and, last but not least, animal welfare. This support, however, depends on strict adherence to the 3Rs (replace, refine, reduce) principle, described in a 2005 report by the Nuffield Council on Bioethics (see Nature 435, 392; 2005). This is aimed to minimize animal numbers, pain, suffering and lasting harm.

A recent set of News Features on animal research ("A matter of life and death" Nature 444, 807-816; 2006) identified considerable scope for advancing the $3 \mathrm{Rs}$, which crucially depends on an effective spread of relevant knowledge and techniques. Several specialist journals - such as Laboratory Animals, Lab Animal and ALTEX - publish research aimed at advancing the 3 Rs criteria, but their readership and impact are limited. Regulators and animal-care committees do not have the means to broadcast and implement novel techniques effectively. Many useful refinements are developed and applied by single labs, but do not get published because they were not a primary focus of the research or because they are not sufficient for a paper on their own. Much relevant information might thus never become widely available within and between these communities.

Most scientific journals require a statement of adherence to legal and institutional animal welfare guidelines. Some have their own codes of practice and ethical committees to guarantee high animal-welfare standards in published material (see, for example, Animal Behaviour at http://asab.nottingham.ac.uk/ ethics/guidelines.php).

Journals could play a much more effective part, however, by including a 3Rs section in the methods section of published papers. First, this would allow authors of controversial papers to detail their measures to minimize pain, suffering and lasting harm. Second, it would let them describe novel tools or techniques used in the paper that serve the 3 Rs. Journals could make this 3 Rs section optional, and - depending on the significance and length of the material could either include it in the print version of the paper or make it available online only as accompanying supplementary material.

Leading journals such as Nature could pioneer such a policy. This would be in the best interests of editors, scientists and the public, as well as to the benefit of the experimental animals.

Hanno Würbel

Division of Animal Welfare and Ethology, Institute of Veterinary Physiology, Justus Liebig University of Giessen, 35392 Giessen, Germany

Nature's editorial policy on papers reporting animal experiments is at www. nature.com/authors/editorial_policies/ experimental.html. We welcome readers' comments on this proposal at Nautilus, our author blog: http://blogs.nature.com/ nautilus/2007/03/proposal_for_journals_ to inclu - Editor, Nature.

\section{Scientists need to confront economists about peak oil}

SIR - Your News Feature "That's oil, folks" (Nature 445, 14-17; 2007) highlights the debate over depletion of the world's oil reserves. I would like to make some additional points.

First, the proponents of the peak-oil theory are predominantly Nature's constituency scientists - whereas the vocal opposition are, to a significant extent, economists. They seem to believe that the geological reality of finite conventional oil resources and the thermodynamic constraints on energy production from alternative hydrocarbon sources can be overcome by a sufficiently high price signal.

Second, there are many statistical and energy-production data supporting predictions of imminent energy decline. For example, a chart of annual discoveries of oil during the twentieth century shows that, despite tremendous advancement in discovery and extraction technology during this period, oil discoveries have been on a downwards trend for nearly 50 years (see ASPO Newsletter 73; January 2007). Although huge, non-conventional oil resources exist - for example: tar sands, shale oil and even biofuels - harvesting these resources is likely to produce little or no energy profit.

Third, scientists warning of energy decline are seriously disturbed by this issue, for many reasons. One is the annual increase in the world's human population. Until recently this has been sustained by increasing grain production, made possible by the oil-driven 'green revolution'. However, grain consumption now exceeds production and reserves are dwindling rapidly. The availability of food will be further eroded by the diversion of grain to production of biofuel.

Most people lack sufficient scientific training to appreciate the strong evidence for, and dire consequences of, an imminent decline in oil production. They are easily lulled into complacency by those with a vested interest in delaying any mitigating responses. The scientific community must unite behind the issue of energy decline. Michael Lardelli

School of Molecular and Biomedical Science, University of Adelaide, North Terrace, Adelaide, South Australia 5005, Australia

\section{Concept of a bacterium still valid in prokaryote debate}

SIR - Nigel Goldenfeld and Carl Woese, in their Connections Essay "Biology's next revolution" (Nature 445, 369; 2007), seek a change in concepts of 'organism, species and evolution' because of the prevalence of lateral gene transfer among bacteria. However, it has been clear for half a century that biological species are epiphenomena of sex, and exist only in sexual eukaryotes - but not in bacteria, which transfer genes laterally without sexual cell fusion. The essay exemplifies a common linguistic confusion caused by those who wish to equate microbes and prokaryotes (see W. Martin and E. V. Koonin Nature 445, 21; 2007).

This state of affairs acutely highlights the continued need for the classical 'concept of a bacterium' (prokaryote) put forward by R. Y. Stanier and C. B. van Niel (Arch. Mikrobiol. 42, 17-35; 1962). The inapplicability of biological species claimed for 'microbes' generally is emphatically not true for sexual protists (eukaryotic microbes). There are even more positive characters shared by all prokaryotes (for example, chromosomes attached to surface membranes) than noted by Martin and Koonin. The only circumstance in which we could reasonably abandon the term 'prokaryote' would be if the biological community as a whole were to accept the traditional use of 'bacteria' instead to embrace both archaebacteria and eubacteria.

The real need is not for a 'revolution' in language and change in the classical concept of an organism, but for molecular evolutionists to make a more serious attempt to understand it. Organisms are not mere assemblages of genes, whether inherited vertically or laterally, but cells (or integrated assemblies of cells) in which there is a mutualistic cooperation of genomes, membranes, skeletons and catalysts that together make a physically and functionally coherent unit capable of reproduction and evolution. Thomas Cavalier-Smith Department of Zoology, University of Oxford, South Parks Road, Oxford OX13PS, UK

\section{Faulty logic}

SIR - Gregory C. Beroza, in his Book Review of Richter's Scale by Susan Hough (Nature 445, 599; 2007), observes that Hough is on "shaky ground" when she uses extrapolation to explain Charles Richter's "many idiosyncrasies and indiscretions".

Seismologists, including Hough, are surely familiar with being on shaky ground.

Alex C. W. May

Northwest Institute for Bio-Health Informatics, University of Manchester, Oxford Road, Manchester M13 9PT, UK 